\title{
Article
}

\section{Comparative Study of Excavation Length Effect on Stope Sta- bility in Underground Mining}

\author{
Huawei Xu ${ }^{1}$, Derek B. Apel 1,*, Yuanyuan Pu ${ }^{2}$ \\ 1 School of Petroleum and Mining Engineering, University of Alberta, Edmonton, Canada; hx1@ualberta.ca \\ 2 State Key Laboratory of Coal Mine Disaster Dynamics and Control, Chongqing University, Chongqing, \\ China; yuanyuanpu@cqu.edu.cn \\ * Correspondence: dapel@ualberta.ca
}

\begin{abstract}
Numerical simulation is a powerful method to study excavation-induced stress redistribution in civil, mining, and underground geotechnical engineering. Also, the numerical simulation method can be time-consuming, especially for large-size three-dimensional models. In the field practice, underground tunnel excavation is proceeded meter by meter, while in the numerical simulation method analysis, it can speed up the excavation process. Furthermore, rational tunnel excavation length in the numerical simulation can provide important references for the in-situ field activities. In this paper, one hard rock underground mine is chosen for the study, and five different excavation length scenarios are proposed and performed to study the effect of excavation length on the stope stability in mining stopes in the numerical simulation method. Displacement, major principal stress, and damage initiation of the stope sidewalls are chosen as the indicators for comparison among the five different excavation scenarios. Also, the CPU time consumed for the simulation of the excavation process is taken into consideration. Compared with the other four excavation scenarios, scenario SCN\#1 is more effective and efficient in numerical excavation simulation, especially for the numerical modeling simulation of a large size underground mine.
\end{abstract}

Keywords: underground engineering; numerical simulation; excavation length effect, major principal stress; displacement; damage initiation; CPU time

\section{Introduction}

As underground mining works progress into deeper and more complex geological environments, they are experiencing more significant stress-induced rock damage initiation problems, which on occasion have seriously complicated effective and efficient mining [1]. Most of the tunnels experience time-dependent convergence; to better understand this behavior and deal with the possible rock mass damages during the excavation process of tunnels, many researchers are actively addressing these issues using many methods, such as analytical, empirical, and numerical methods. Barla et al. [2-4] proposed various approaches for tunnel design by assessing the interaction between rock mass and structures in the short-term and long-term in a rock mass with time-dependent squeezing behavior. Rock mass squeezing phenomenon around the tunnels are widely studied by considering the various rates of advancing [5], analyzing the extension of microcrack length and development of EDZ [6,7], time-dependent deformation, and elastoplastic behavior [8], in the means of semi-empirical back-analyze approach [9], analytical solution [10], and numerical model $[5,6,9,11,12]$. The interaction mechanism between the tunnel excavation and tunnel stability is studied by analyzing the supports and reinforcements, model tests, underground research laboratory measurement, and numerical simulation [13-16]. Kielbassa [17] proposed a simplified two-steps plane model approach to determine the stresses and deformations of circular and non-circular tunnels during the excavation process. Gioda [18] discussed the linear and non-linear viscous constitutive laws and 
developed numerical methods to analyze the time-dependent effect on performance in squeezing rocks.

In underground mining, stopes are excavated step by step and one by one. Usually, researchers focus on only several stopes and develop simple models to study the excavation-induced stress redistribution and displacement. For many cases, two-dimensional (2D) models are used to assess the analysis quickly. However, all the stopes in underground mining will be affected by the excavation of the adjacent stopes in three directions/dimensions, and then the 2D models cannot represent the real stress situation. Therefore, understanding the three-dimensional (3D) redistribution of excavation-induced stresses becomes essential given the adverse consequences such stresses will have on the host rock strength and the subsequent excavation stability. Using a three-dimensional finite element numerical model can better predict the near-field stress paths [19] and potential rockburst during the excavation process $[20,21]$.

Furthermore, predicting mining-induced surface subsidence [20], analyzing time-dependent mechanical behavior of the Excavation Damage Zone (EDZ) [22], studying pore pressure distributions [23], stresses and deformations in the lining during the shielddriven tunnel excavation $[15,23]$ can also be done using finite element modeling. To improve the tunnel stability, Kaiser [1] provided an overall framework for assessing the stability of underground openings in hard rocks, regardless of whether the excavations are required for mining, nuclear waste, or civil engineering applications. Langford [24] suggested the guidelines to determine the excavation damage zones (EDZs) by discussing the rock properties and analyzing the statistical distribution of the dimensions in the process of underground excavation.

Researchers have done a lot to analyze the time-dependent convergence effect of the tunnels, the mechanism between the tunnel excavation and tunnel stability, reinforcement stability, et al. Though numerical modeling is powerful, sometimes it is time-consuming, especially running a large size three-dimensional (3D) numerical model to analyze the effect of the whole excavation process on the ground displacement and stress redistribution. Increasing the excavation length at each step can be an option to save time to run the numerical modeling analysis. While, whether the extended excavation length causes the same displacement and stress redistribution is rarely discussed. This paper proposes and presents five different excavation scenarios with various excavation lengths at six different mining levels to conduct this study.

\section{Background and Methods}

\subsection{Numerical model configuration}

For this study, a hard rock underground mine located in northern Canada was chosen. The mine in this study was initially operated as an open-pit mine. Once the open-pit mining was completed, the operation shifted to underground mining using the blasthole stoping (BHS) mining method. Under the open pit, there is the mining pipe: MP\#1. Compared with the 2D numerical model, the 3D model can estimate the deformations of underground openings, predict the mining-induced surface subsidence and potential rockburst, and explore the near-field stress paths during the excavation [19-22]. A full-size 3D elastoplastic finite element numerical model was developed, and the model has a size of $1200 \mathrm{~m}$ in length, $1200 \mathrm{~m}$ in width, and $700 \mathrm{~m}$ in depth. The mining depths of the six analyzed mining levels are: $-210 m,-240 m,-270 m,-300 m,-330 m,-360 m$, from mining level L\#501 to mining level L\#506, respectively. This numerical simulation was conducted by the codes of ABAQUS [25]. The Mohr-Coulomb failure criterion was applied since it was accepted as the default criterion for rock mass in ABAQUS [25]. The boundary condition is applied on the bottom of the model, and the top surface is set to be free, and on the four vertical boundaries, horizontal restraints on both $X$ and $Y$ directions are applied. The tennode quadratic tetrahedron mesh type (ET: C3D10) [25] was used to achieve better mining-induced redistributed stress and ground subsidence results. There are thirteen mining 
levels, and six of these are chosen as the analyzed levels for this study, as shown in Figure 2.1 .
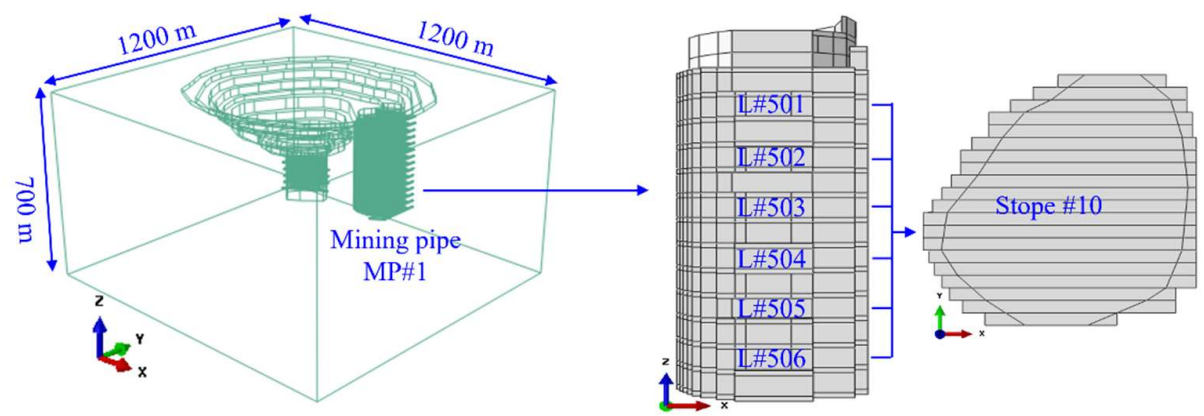

Figure 2.1. FE model of the mine site

\subsection{Mechanics properties of materials}

Table 1 shows the material properties used in the model $[20,21,26,27]$. The host rock in the hard rock mine is granite. Here, $\gamma$ is the unit weight, $C$ is the cohesive strength, $\phi$ is the angle of friction, $E$ is the elastic Young's modulus, $v$ is the Poisson's ratio, and $\sigma_{c}$ is the uniaxial compressive strength (UCS).

Table 1. Material properties

\begin{tabular}{ccccccc}
\hline Rock Mass & $\begin{array}{c}\gamma \\
\left(\mathbf{M N} / \mathbf{m}^{3}\right)\end{array}$ & $\begin{array}{c}\mathbf{C} \\
\mathbf{( M P a})\end{array}$ & $\begin{array}{c}\boldsymbol{\phi} \\
\left({ }^{\circ}\right)\end{array}$ & $\begin{array}{c}E \\
(\mathbf{G P a})\end{array}$ & $v$ & $\begin{array}{c}\boldsymbol{\sigma}_{\mathbf{c}} \\
(\mathbf{M P a})\end{array}$ \\
\hline MP\#1 & 0.024 & 4.2 & 26.4 & 18.7 & 0.26 & 66 \\
Granite & 0.026 & 9.3 & 45 & 24 & 0.3 & 130 \\
\hline
\end{tabular}

\subsection{Excavation scenarios}

In this study, one stope, named $\# 10$, is chosen as the case study stope, as shown in Figure 2.1. The size of this stope is $8 \mathrm{~m} \times 20 \mathrm{~m} \times 150 \mathrm{~m}$ (width $\times$ height $\times$ length). Five different excavation length scenarios are proposed and conducted to complete this study. For the excavation scenario, SCN\#1 has only one part (P1), and this part is the whole \#10 stope; the excavation length is $150 \mathrm{~m}$. Scenario SCN\#2 has two equal parts, and each part is $75 \mathrm{~m}$ long. Scenario SCN\#3 has three equal parts, and each part is $50 \mathrm{~m}$ long. Finally, scenario SCN\#4 has four equal parts, and scenario SCN\#5 has five equal parts, and each part is 37.5 $\mathrm{m}$ and $30 \mathrm{~m}$ long, respectively, as shown in the following Figure 2.2. During the simulation of the excavation process, these parts will be excavated one by one.
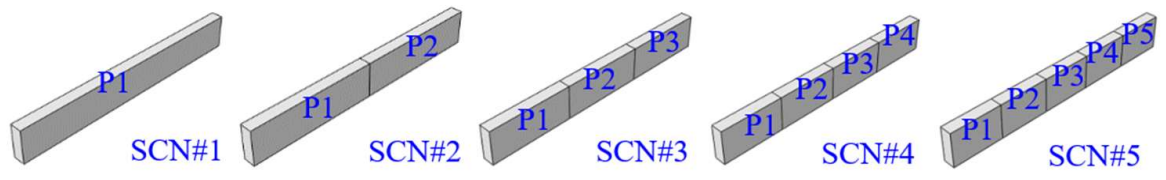

Figure 2.2. Five excavation scenarios of stope $\# 10$

In all five excavation scenarios, the first simulation step, step1 (S1), is the geostatic step to calculate the initial state of stress before excavation. For the excavation scenario,

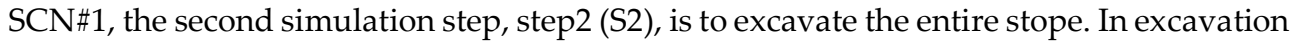
scenario SCN\#2, it takes two steps S2 and S3, with S2 excavating P1 and S3 excavating P2, to complete the excavation of the stope. Following this logic, the excavation scenarios SCN\#3 and SCN\#4 take four and five steps to excavate the stope, respectively. Finally, 
excavation scenario SCN\#5 takes five equal steps, S2, S3, S4, S5, S6, to finish the excavation. Table 2 presents the simulation scenario steps for excavation.

Table 2. Five different excavation scenarios

\begin{tabular}{ccccccc}
\hline Scenario & Part-1 & Part-2 & Part-3 & Part-4 & Part-5 & Step \\
\hline SCN\#1 & Y & N & N & N & N & 2 \\
SCN\#2 & Y & Y & N & N & N & 3 \\
SCN\#3 & Y & Y & Y & N & N & 4 \\
SCN\#4 & Y & Y & Y & Y & N & 5 \\
SCN\#5 & Y & Y & Y & Y & Y & 6 \\
\hline
\end{tabular}

Note: Here, Y stands for yes, N stands for no. Step stands for the steps needed to complete excavation simulation

\section{Excavation length effect on displacement}

Displacement is a representative explicit and significant factor in indicating the rock mass's damage in the stopes caused by the excavation process. In this paper, the displacements of the two sidewalls of the excavated stopes are presented to investigate the effects of the proposed five different excavation scenarios among the six different mining levels. To present the results of the different excavation scenarios, the figures presented in the following part of this paper have the same x-axial, from steps S1 to S6. In addition, the final state of displacements caused by the five different excavation scenarios among the six mining levels is also presented in the following figures in this part.

\subsection{Displacement of a chosen point on the left sidewall of the stope}

Figure 3.1.1 shows the displacement of the chosen point on the left sidewalls of the stopes of both mining levels L\#501 and L\#502. Following the excavation process, from excavation step S2 to step S6, the displacement increases constantly. For mining level $\mathrm{L} \# 501$, the final displacements are almost the same and are less than $6 \mathrm{~mm}$ for all the five different excavation scenarios. However, the displacement presents a similar trend in mining level L\#502, while the final displacements are more extensive than that of L\#501 mining level and are over $6 \mathrm{~mm}$.
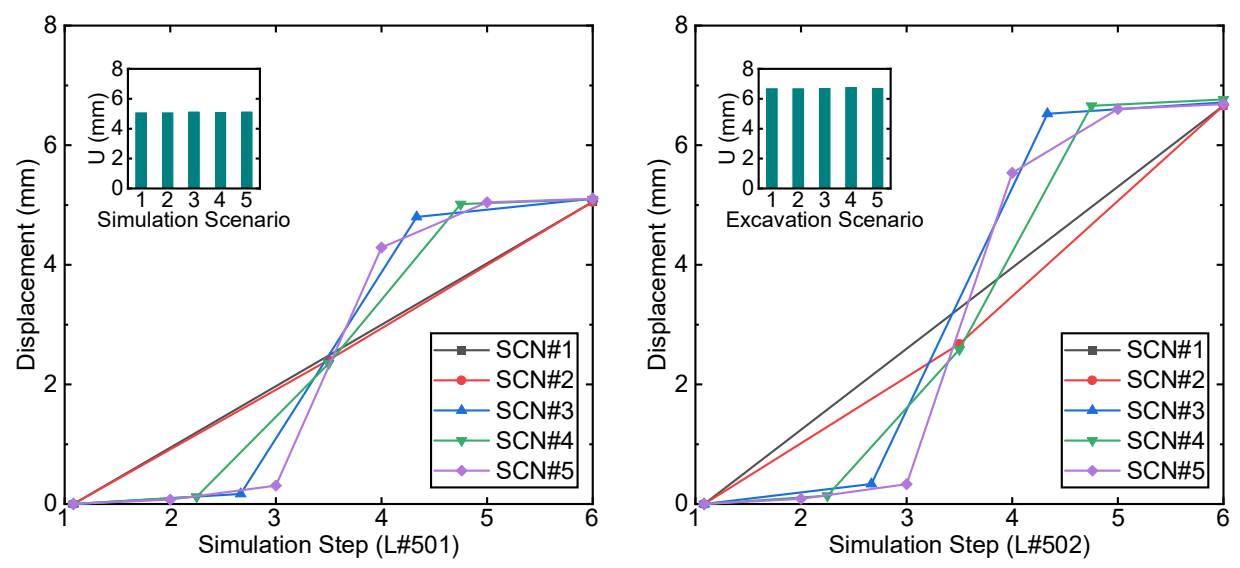

Figure 3.1.1. Displacement of the left sidewall of \#10 stope in level L\#501 and L\#502

Figure 3.1.2 shows the displacement of stope sidewalls in mining levels L\#503 and $\mathrm{L} \# 504$. These two levels present almost the same change trend of displacement. However, mining level L\#503 has a less than $9 \mathrm{~mm}$ final displacement, while mining level L\#504 has an over $9 \mathrm{~mm}$ final displacement. 

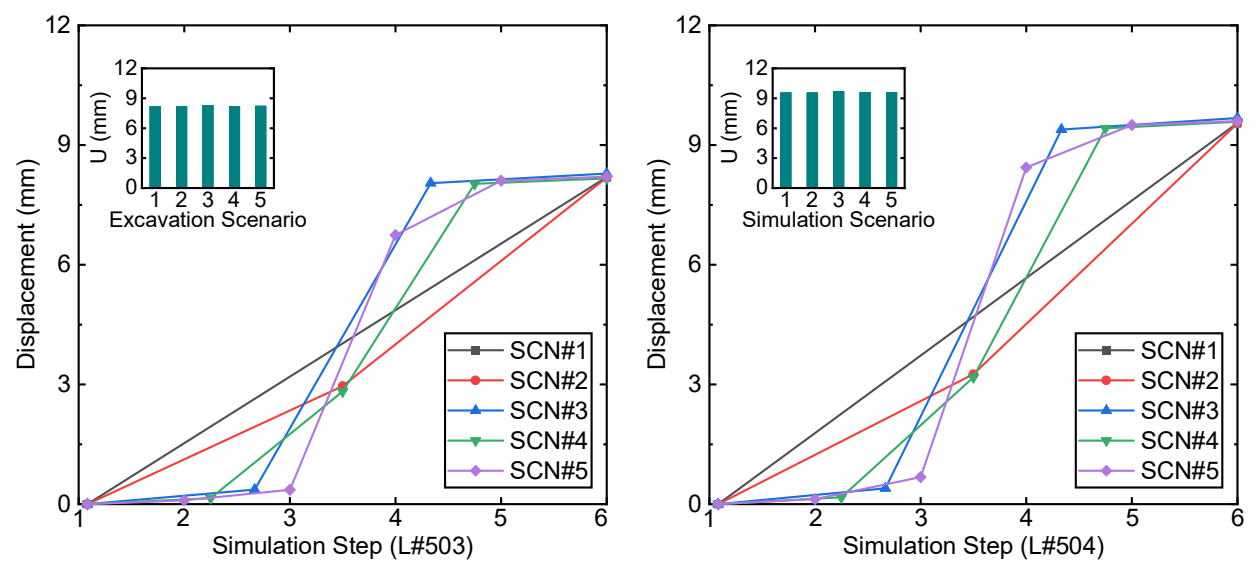

Figure 3.1.2. Displacement of the left sidewall of \#10 stope in level L\#503 and L\#504

Displacements of mining level L\#505 and level L\#506 present a whole similar trend. While, for scenario SCN\#4 at both level L\#505 and level L\#506, it shows a difference with the trends presented in the other four mining levels, as shown in Figure 3.1.3. Both levels have a final displacement of around $12 \mathrm{~mm}$, larger than the displacement in the other four mining levels.
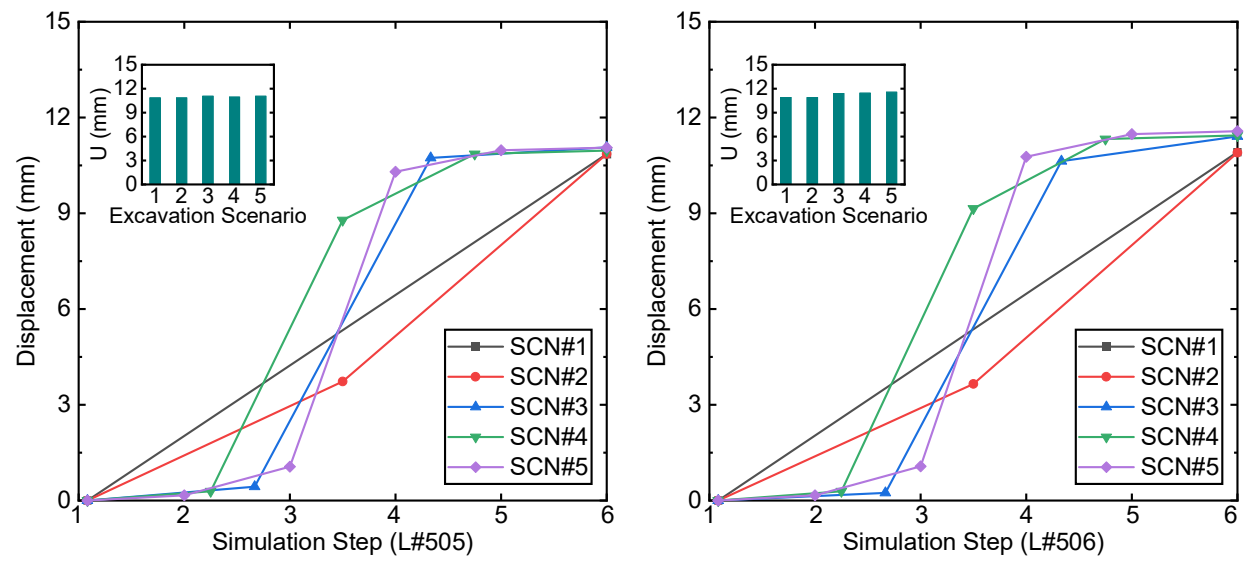

Figure 3.1.3. Displacement of the left sidewall of \#10 stope in level L\#505 and L\#506

According to the above six figures, the displacements of the left sidewall of the stopes at each mining level caused by the five different excavation scenarios have the same final displacement value. With the increase of the mining depth, from mining level L\#501 to level L\#506, the displacement constantly increases from around $6 \mathrm{~mm}$ to over $12 \mathrm{~mm}$, a double increase. From mining level L\#501 to level L\#506, the final excavation steps cause no displacement increase for scenarios: SCN\#3, SCN\#4, and SCN\#5.

\subsection{Displacement of a chosen point on the right sidewall of the stope}

Compared with the stope's left sidewall displacement, the stope's right sidewall sees a smaller final displacement at both mining levels L\#501 and L\#502. The final displacement of the right sidewall of level L\#501 is less than $5 \mathrm{~mm}$, and the final displacement of level L\#502 is over $6 \mathrm{~mm}$. Thus, the final displacement among the five excavation scenarios at each mining level is almost the same, as shown in Figure 3.2.1. 

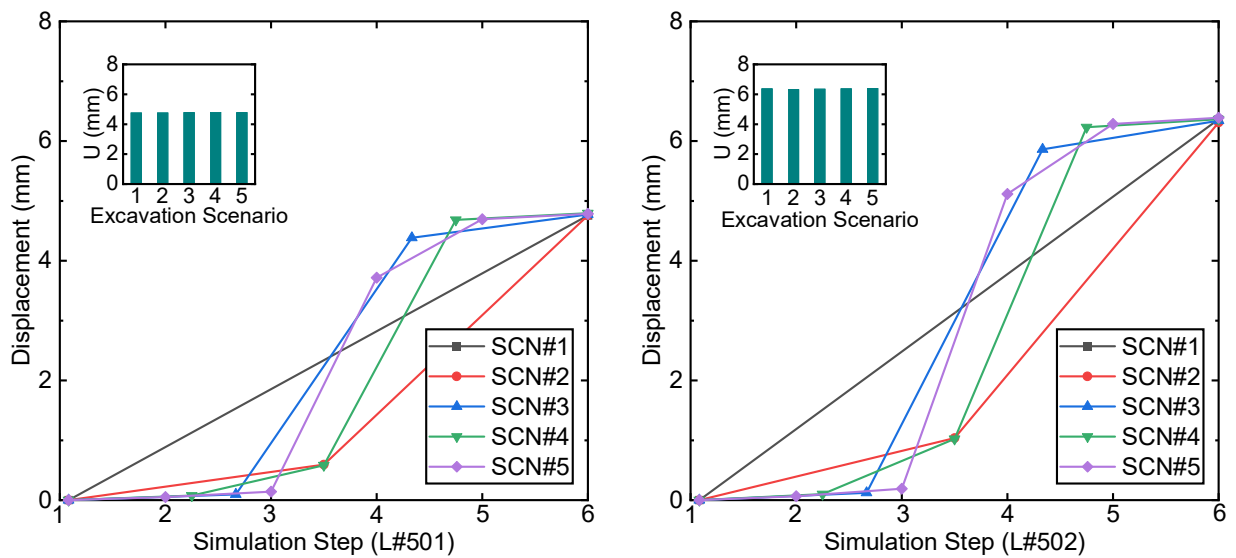

Figure 3.2.1. Displacement of the right sidewall of \#10 stope in level L\#501 and L\#502

For mining level \#503, the displacement of the right sidewall is almost the same as that of the left sidewall, which is $8 \mathrm{~mm}$. Similarly, the displacements of both sidewalls of mining level L\#504 are around $9.5 \mathrm{~mm}$. Also, as shown in Figure 3.2.2, the displacement trends are similar according to the process of excavation.
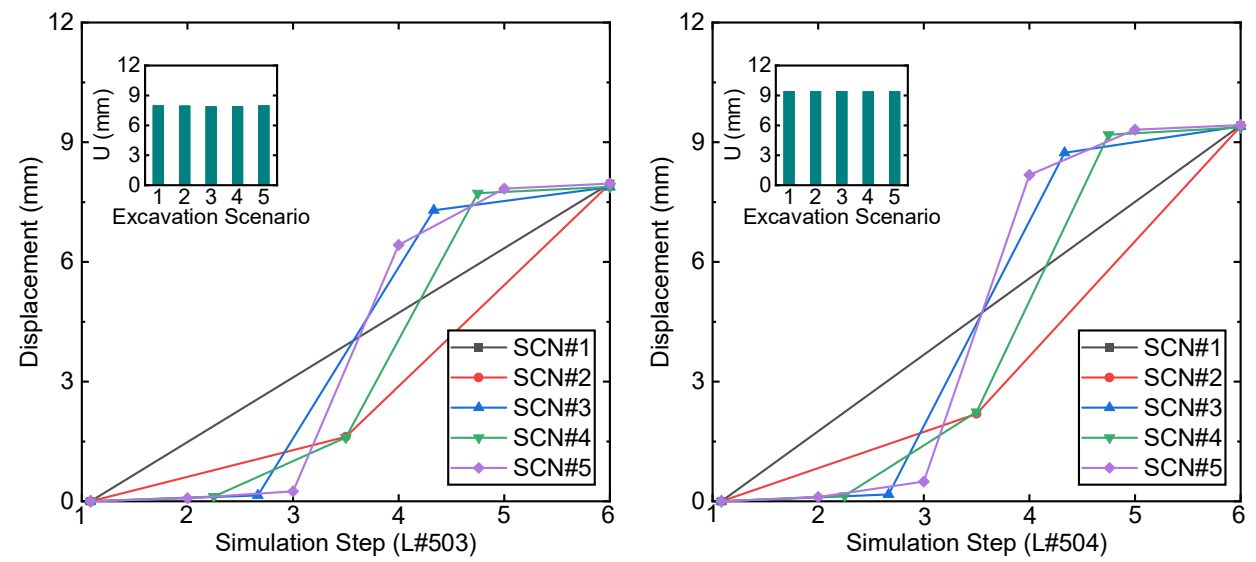

Figure 3.2.2. Displacement of the right sidewall of \#10 stope in level L\#503 and L\#504

Figure 3.2.3 shows the displacement trends of the right sidewall of the stope of mining level L\#505 and L\#506. The displacements are between $10 \mathrm{~mm}$ and $11 \mathrm{~mm}$, and smaller than that of the left sidewall. For excavation scenarios SCN\#3 and SCN\#5, there is a significant increase during the excavation of steps S2/S3, respectively.
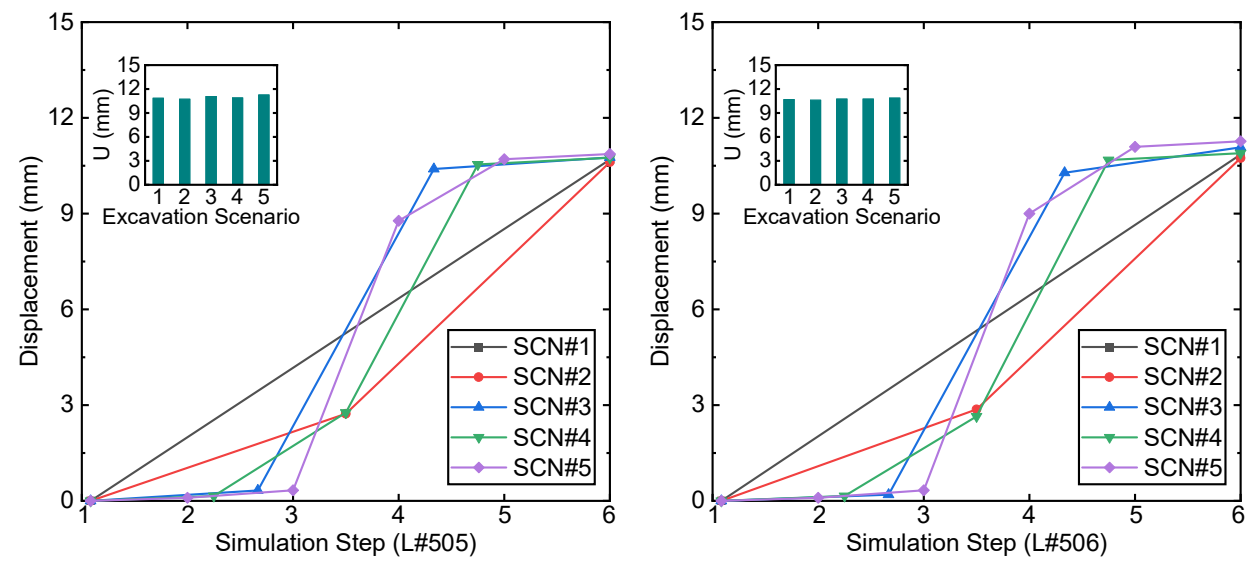
Figure 3.2.3. Displacement of the right sidewall of \#10 stope in level L\#505 and L\#506

According to the excavation-caused displacements of the two sidewalls of the stopes presented in this section, the excavation processes cause almost the same displacement at the monitored points at each mining level. Unlike SCN\#1 and SCN\#2, the last exaction step in the other three excavation scenarios does not cause an increase in displacement.

\section{Excavation length effect on principal stress}

Stope excavation in underground engineering causes stress redistribution. The redistributed stress may cause damage to the around rock mass in the stopes, even causes rockburst. The major principal stress contributes the primary factor resulting in the rock mass damage. Then the significant principal stress can be listed as a critical factor in assessing the rock mass's potential damage.

\subsection{Major principal stress of chosen point on left sidewall of the stope}

As presented in Figure 4.1.1, the major principal stress starts to change from the same intact stress condition at geostatic step S1. After finishing the last excavation step, the major principal stress trends reach almost the same finial stress condition, increasing and decreasing during the excavation process. For mining level L\#501, the final major principal stresses are less than $4 \mathrm{MPa}$ for all five excavation scenarios. For mining level L\#502, the final major principal stresses are over $4 \mathrm{MPa}$ among the five excavation scenarios.
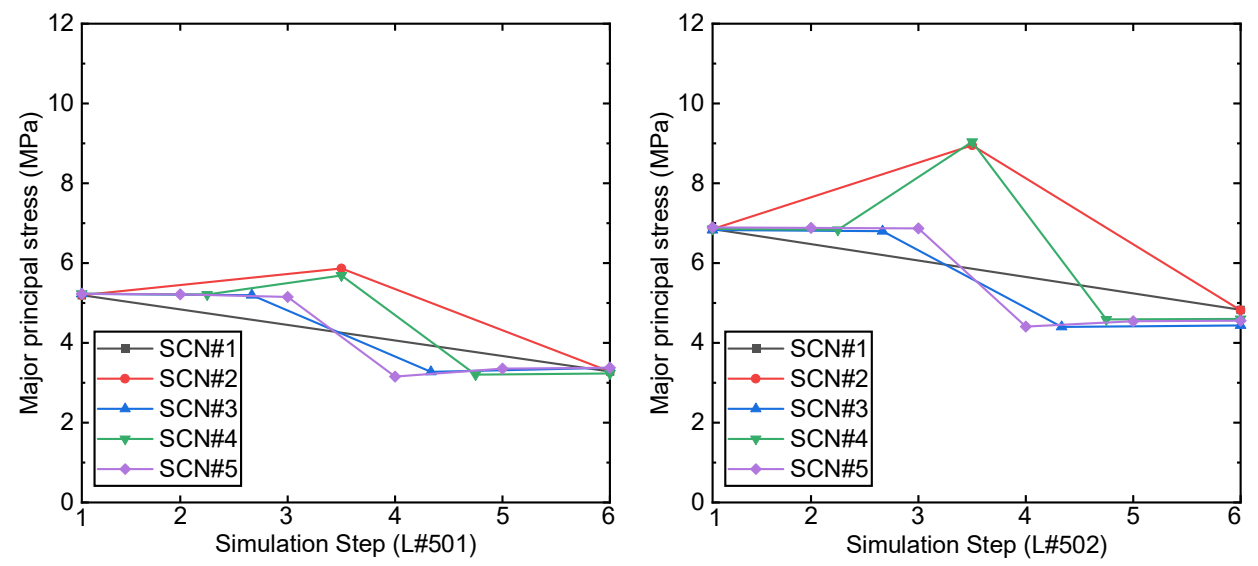

Figure 4.1.1. Major principal stress of left sidewall of \#10 stope in level L\#501 and L\#502

Figure 4.1.2 shows the major principal stress changes of mining level L\#503 and level $\mathrm{L} \# 504$, and the trends are similar. Starting from 8.5 MPa at step S1 and finishing at around $5 \mathrm{MPa}$, the major principal stress of mining level L\#503 sees an average $38 \%$ decrease among all the five excavation scenarios during the excavation process. For mining level L\#504, among the five excavation scenarios, the major principal stress has an almost same percentage of stress decrease as mining level L\#503, though it starts from over $9 \mathrm{MPa}$ and finishes at around $6 \mathrm{MPa}$. 

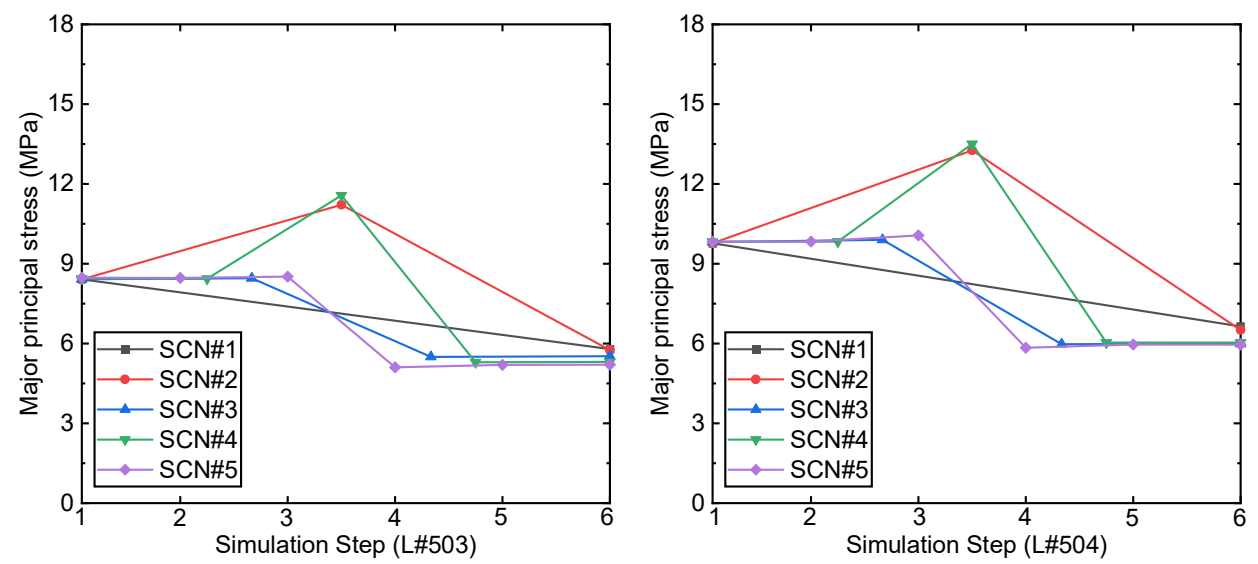

Figure 4.1.2. Major principal stress of left sidewall of \#10 stope in level L\#503 and L\#504

With the mining level going deeper, the intact major principal stress increases. The trends of the major principal stress of both mining level L\#505 and level L\#506 are similar. Also, the final major principal stresses are very close to the completion of excavation. Unlike the other four mining levels, at mining level L\#505 and L\#506, only scenario SCN\#2 has a significant increase of the major principal stress during the excavation process of step S2. The major principal stress has an average of $40 \%$ release after the excavation, as shown in Figure 4.1.3.
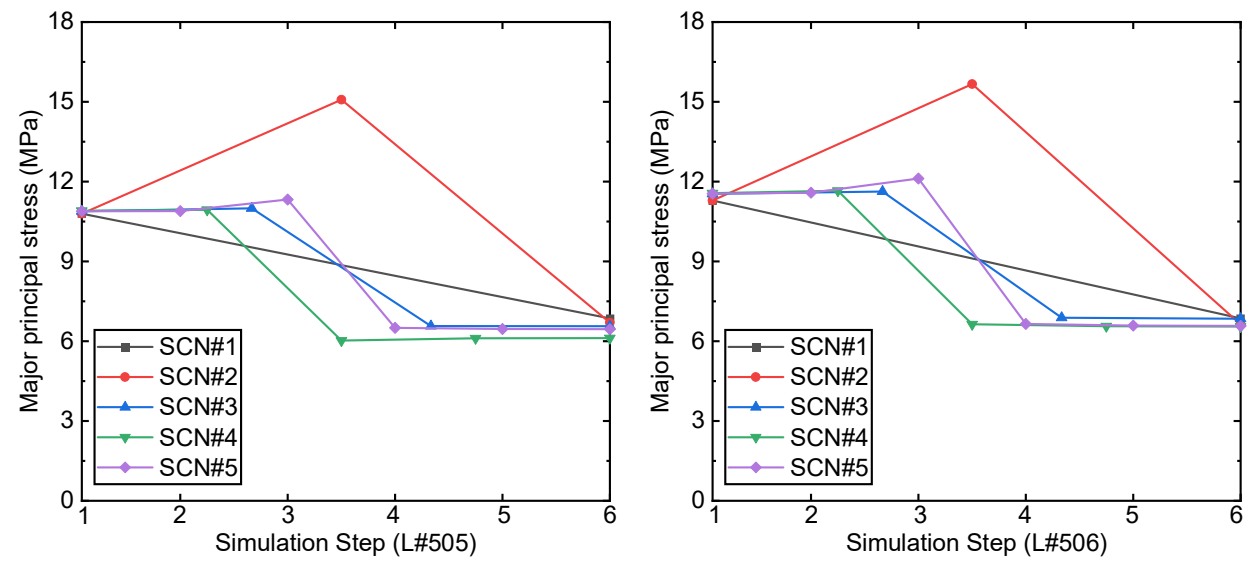

Figure 4.1.3. Major principal stress of left sidewall of \#10 stope in level L\#505 and L\#506

As can be seen from the above three figures, the intact major principal stress condition at geostatic step S1 constantly increases with the increase of the depths of mining levels. Therefore, with the increase of the depth of mining levels, scenario SCN\#2 has a gradually significant increase of the major principal stress during the excavation process of step S2. In contrast, for excavation scenarios SCN\#3, SCN\#4, and SCN\#5, the major principal stresses only to witness a slight increase during the excavation process. Also, the final major principal stresses are smaller than that of the intact stresses, which is suitable proof of the stress release caused by the excavation process.

\subsection{Major principal stress of chosen point on right sidewall of the stope}

Similar to the displacement situation, the major principal stresses of the right sidewalls of the stopes are almost the same as the stresses of the left sidewalls at each mining level. However, unlike the left sidewalls, the major principal stresses of the right sidewalls 
significantly increase during the excavation process for scenarios SCN\#2 and SCN\#4 of mining level L\#501 and level L\#502, as shown in Figure 4.2.1 and Figure 4.1.1. Mining level $\mathrm{L} \# 501$ sees a $34 \%$ decrease from the intact stress to the finial stress during the excavation steps, and mining level L\#502 has an average 32\% decrease of stress among the five scenarios.
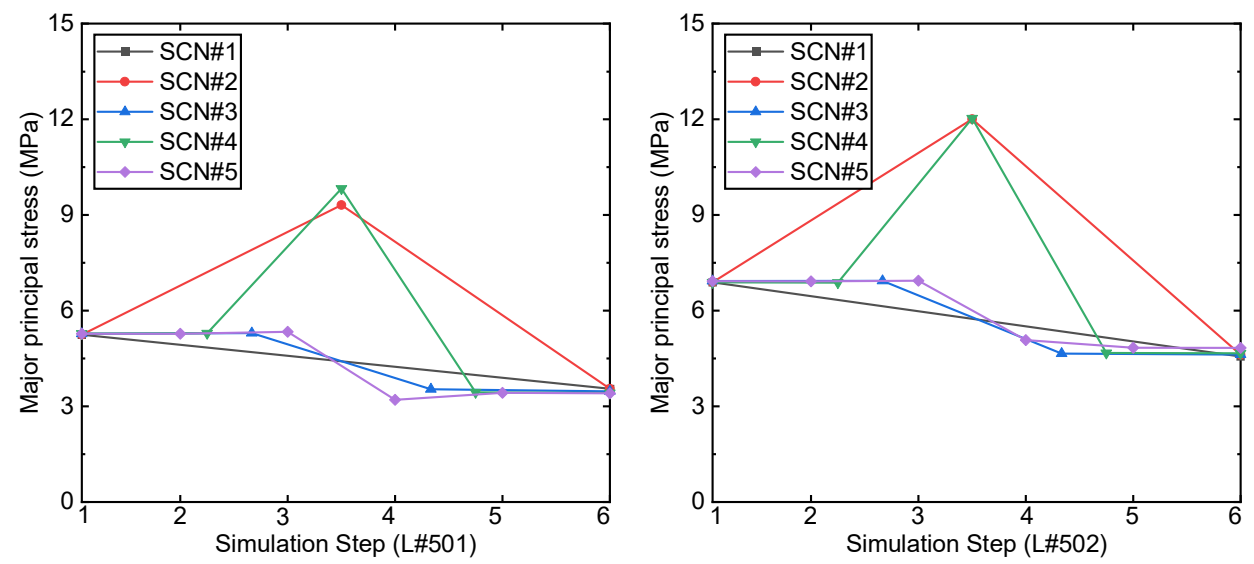

Figure 4.2.1. Major principal stress of right sidewall of \#10 stope in level L\#501 and L\#502

Starting from around $9 \mathrm{MPa}$ and ending at $5.5 \mathrm{MPa}$, the major principal stress of the right sidewall in mining level L\#503 has a 35\% decrease. For mining level L\#504, the major principal stress has an average 33\% decrease, from over $9 \mathrm{MPa}$ to around $6.5 \mathrm{MPa}$. Also, scenarios SCN\#2 and SCN\#4 significantly increase during the excavation process, as shown in Figure 4.2.2.
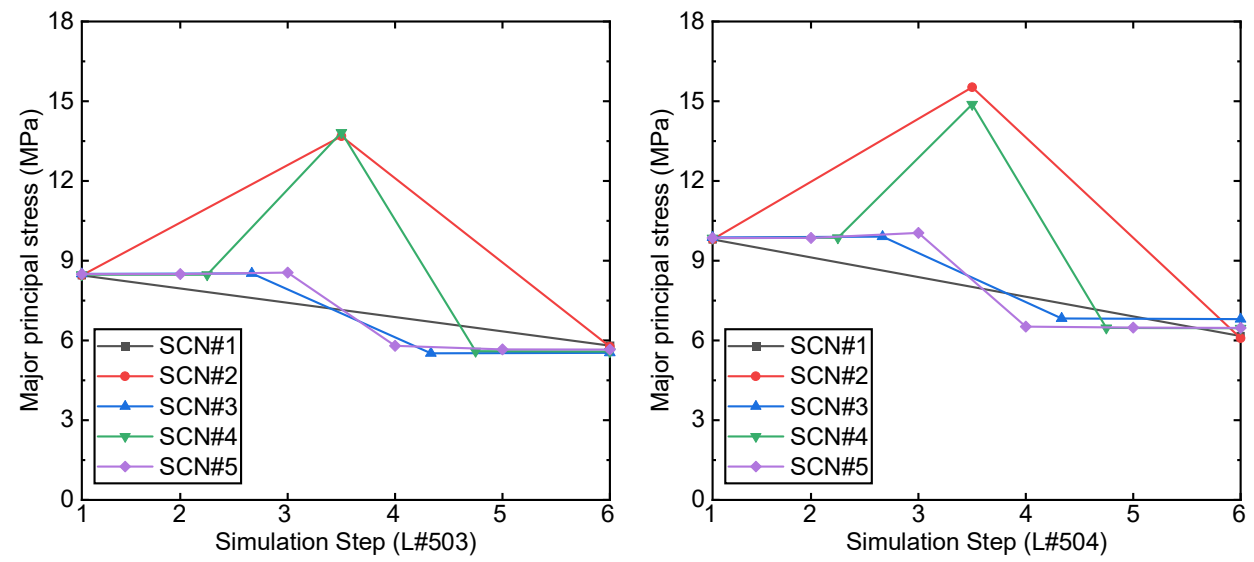

Figure 4.2.2. Major principal stress of right sidewall of \#10 stope in level L\#503 and L\#504

Similar to the other four levels, the excavation scenarios SCN\#2 and SCN\#4 for mining levels L\#505 and level L\#506 significantly increase major principal stress at the excavation step S2/S3, as shown in the following Figure 4.2.3. The intact major principal stresses of both levels are close, and it is around $11 \mathrm{MPa}$. Mining level L\#505 has an average $38 \%$ decrease of major principal stress from steps S1 to S6. Among the five excavation scenarios, the stress decrease of mining level L\#506 is about $41 \%$, from $11.5 \mathrm{MPa}$ to 6.7 $\mathrm{MPa}$, from step S1 to S6. 

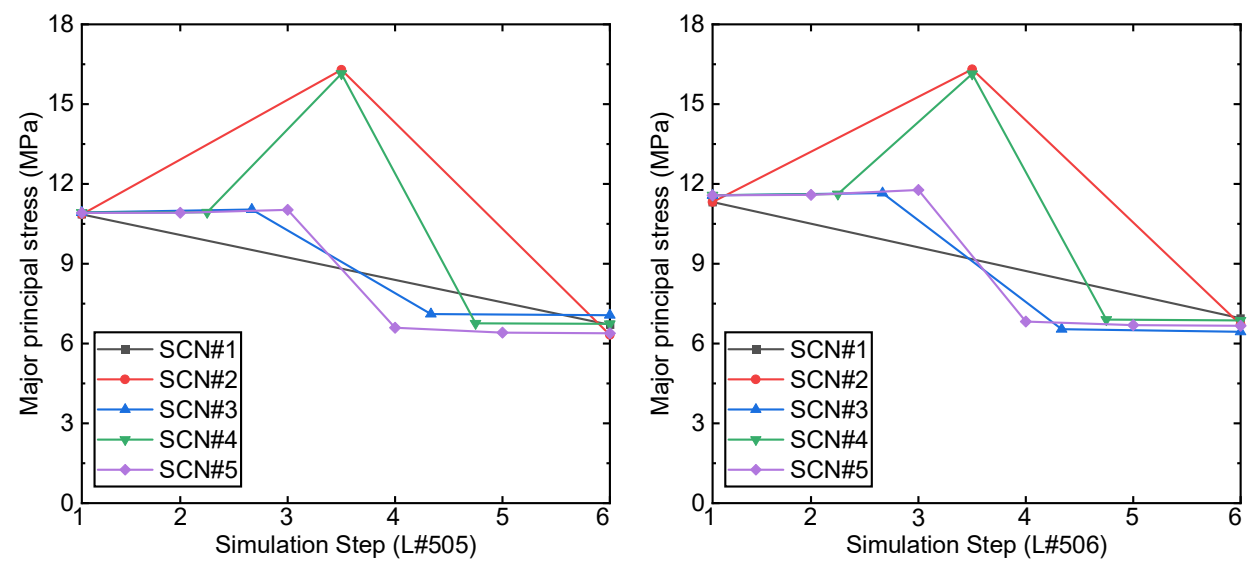

Figure 4.2.3. Major principal stress of right sidewall of \#10 stope in level L\#505 and L\#506

The major principal stresses of the right sidewall at each mining level increase along with the growing depth of mining levels, similar to the left sidewalls' major principal stresses. While different with the left sidewall, all six mining levels significantly increase stress in both scenarios, SCN\#2 and SCN\#4, caused by the excavation step S2/S3. Thus, both sidewalls have almost intact and final major principal stresses among five excavation scenarios at each level.

\section{Excavation length effect on potential damage initiation (DI)}

As Canadian hard-rock mines go deeper, they are experiencing more significant stress-induced rock damage initiation problems, which on occasion have seriously complicated effective and efficient mining. In underground engineering, excavation of stopes will cause stress redistribution and damage initiation. To better assess the damages caused by the redistributed stresses in the stope rock mass, Castro [28,29] proposed a rock mass potential damage initiation (DI) index to assess the potential damage zones around the excavation stope sections.

$$
\sigma \mathrm{DI}=\left(\sigma_{1}-\sigma_{3}\right) / \sigma_{\mathrm{ci}}
$$

here, $\sigma_{D I}$ is the threshold stress for damage stress, $\sigma_{1}$ and $\sigma_{3}$ are the major and minor principal stresses, respectively, $\sigma_{\mathrm{ci}}$ is the uniaxial compressive stress (UCS) of the intact rock tested in the laboratory.

\subsection{Rock mass damage initiation of a chosen point on the left sidewall of the stope}

Figure 5.1.1 shows the rock mass damage initiation around the excavated stopes at mining levels L\#501 and L\#502. The damage initiation (DI) presents a similar trend of the major principal stress. According to the criteria proposed by Castro [28,29], when the value of DI is less than 0.35 , the redistributed stresses will cause no minor rock mass damages. Also, there is no potential for rock strain-bursting. As the levels getting close to the ground surface, the excavation of the stopes only causes minor damages in the rock mass around the stopes. As can be seen in Figure 5.1.1, the DI is very little value. 

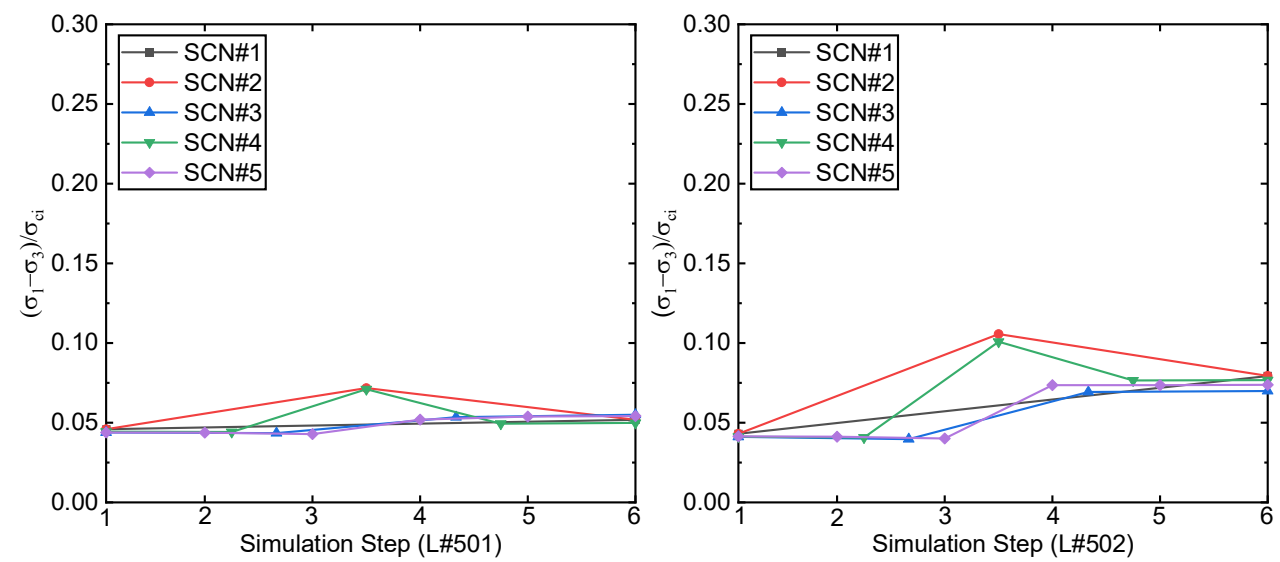

Figure 5.1.1. DI of the left sidewall of \#10 stope in level L\#501 and L\#502

With the increase of the mining depth, the DI grows up while it is still under 0.35. Starting from a DI under 0.05 at step S1, and ending at over 0.1 , at different mining levels among the five excavation scenarios, the damages caused by the excavation in the rock mass around the stopes in mining level L\#503, L\#504, L\#505 and L\#506 are still minor, even the DI witnesses a double increase, as shown in Figure 5.1.2 and Figure 5.1.3.
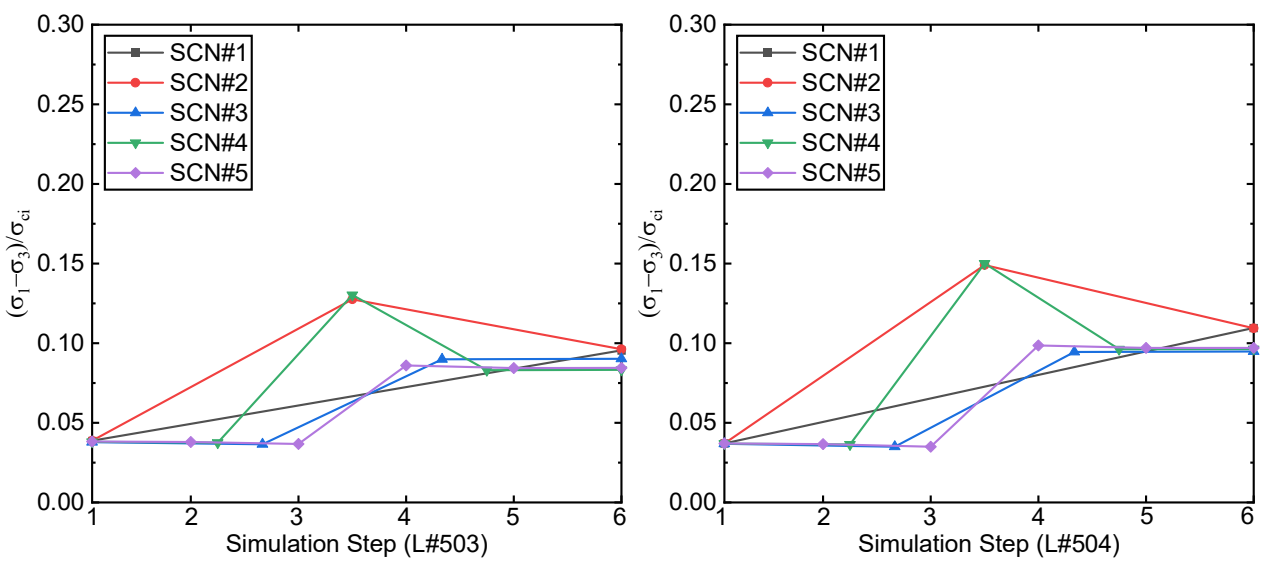

Figure 5.1.2. DI of the left sidewall of \#10 stope in level L\#503 and L\#504
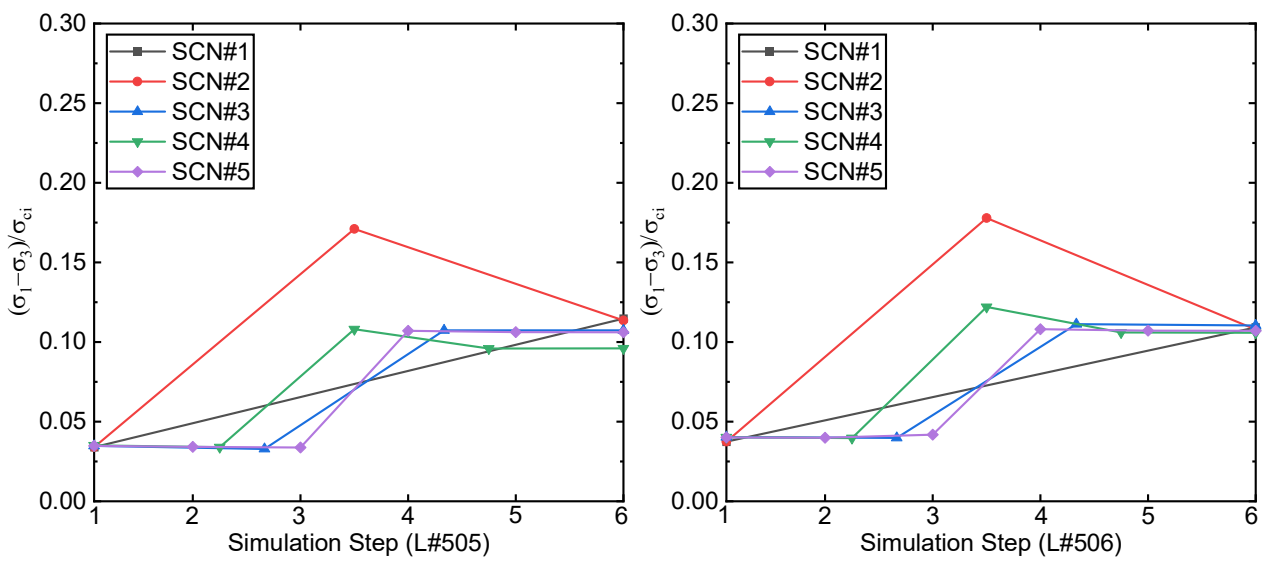

Figure 5.1.3. DI of the left sidewall of \#10 stope in level L\#505 and L\#506 
According to the above three figures, as the mining levels go deeper, the DI increases constantly. While the excavation of the one single stope causes only minor damages to the rock mass around the excavated stopes, even with different excavation scenarios and mining levels.

\subsection{Rock mass damage initiation of a chosen point on the right sidewall of the stope}

Unlike the left sidewall, the DI of the suitable sidewalls of excavation scenarios SCN\#2 and SCN\#4 significantly increased during the excavation of step S2/S3 at level L\#501 and level L\#502, as shown in Figure 5.2.1. While for the other three excavation scenarios, SCN\#1, SCN\#3, and SCN\#5, the changes of DI during the excavation steps are small.
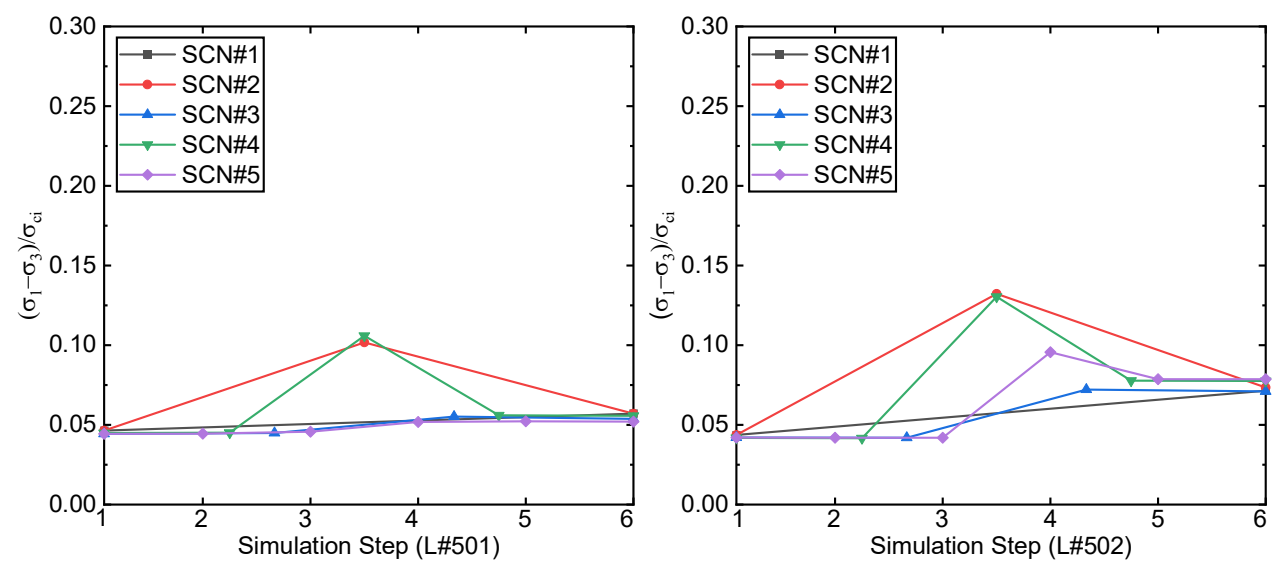

Figure 5.2.1. DI of the right sidewall of \#10 stope in level L\#501 and L\#502

Figure 5.2.2 and Figure 5.2.3 show the DI trend of stopes in mining level L\#503, level $\mathrm{L} \# 504$, level L\#505, and level L\#506 during the excavation process from steps S1 to step S6. Similar to situations in mining level L\#501 and level L\#502, the three excavation scenarios SCN\#1, SCN\#3, and SCN\#5 have a constant increase of the DI during the excavation process, while excavation scenarios $\mathrm{SCN} \# 2$ and $\mathrm{SCN} \# 4$ have a significant increase during the excavation of step S2/S3. Also, the DI starts from around 0.05, and it ends at over 0.1, which may cause minor damages in the rock mass around the excavated stope sections.
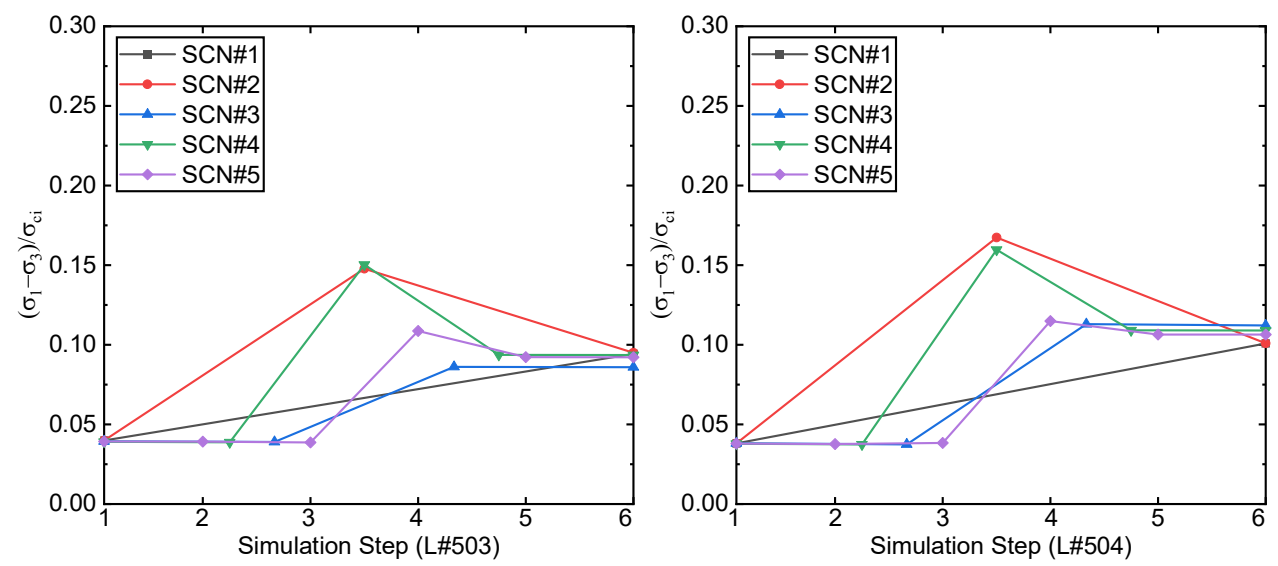

Figure 5.2.2. DI of right sidewall of \#10 stope in level L\#503 and L\#504 

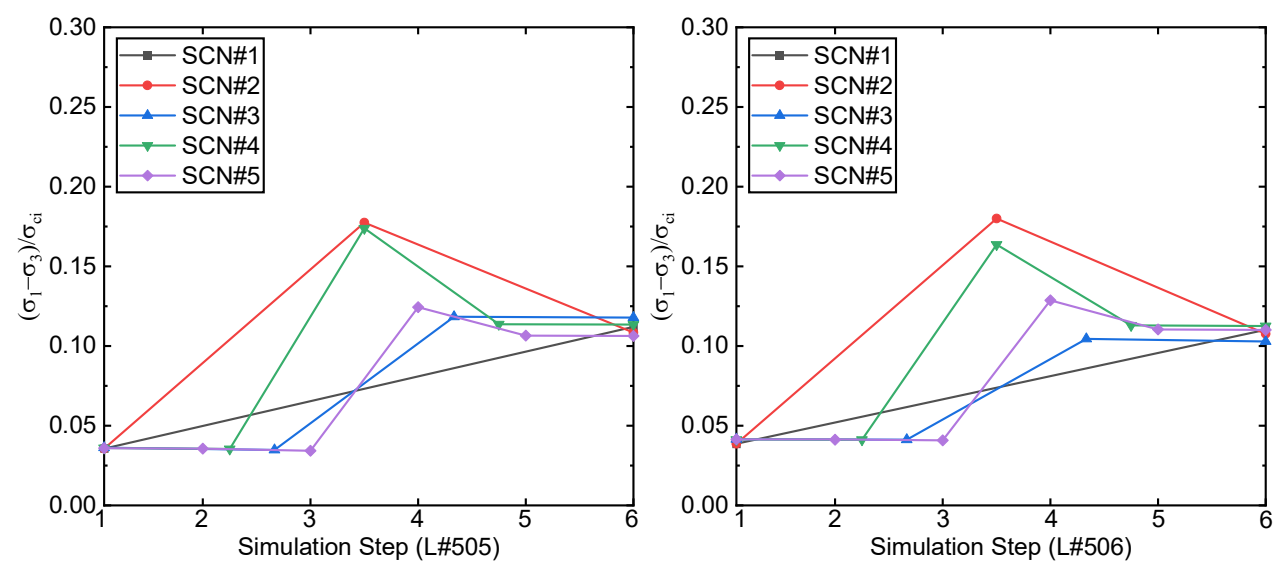

Figure 5.2.3. DI of the right sidewall of \#10 stope in level L\#505 and L\#506

The redistributed stresses caused by the excavation process contribute almost the same damage initiations in the rock mass of two sidewalls around the stopes at each mining level. Thus, although the DI increases twice during the excavation process at both sidewalls, the damages can be assessed on a minor scale.

\section{Comparison of CPU time consumed among different excavation scenarios}

For the numerical simulation method, the CPU time of running the analysis model should be considered. The following Figure 6.1 shows the CPU time used to run the numerical simulation excavation steps. These six different mining levels present a similar trend of CPU time among the five different excavation scenarios. The CPU time constantly increases from excavation scenario $\mathrm{SCN} \# 1$ to $\mathrm{SCN} \# 5$ at each mining level.

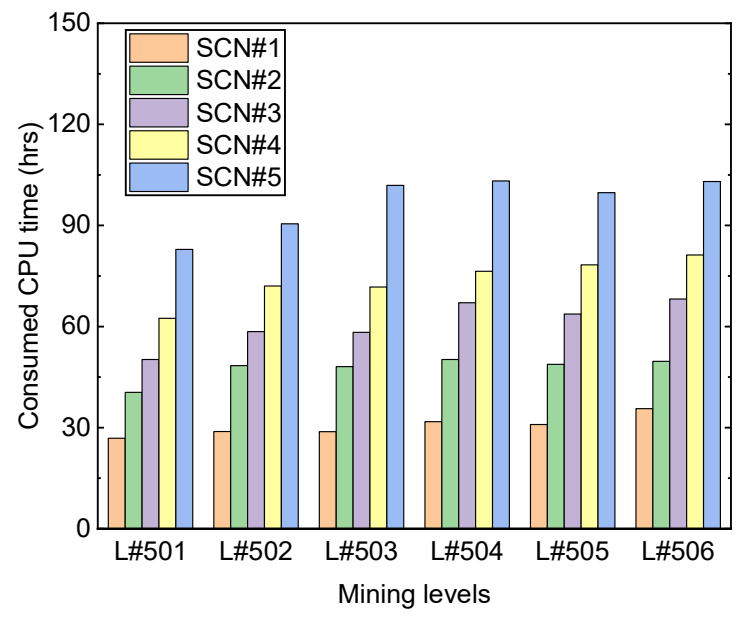

Figure 6.1. CPU time for different excavation scenarios of different mining level

At the same mining level, the CPU time used in excavation scenario SCN\#5 is much more than the CPU time used in excavation scenario SCN\#1. At the excavation scenario SCN\#1, all the CPU times at six different levels are less than 40 hours, while at excavation scenario SCN\#5, the CPU time of mining level L\#501 and mining level L\#502 is more than 80 hours. The CPU time for mining level L\#503, level L\#504, level L\#505, and level L\#506 is over 100 hours among all five excavation scenarios. Figure 6.2 shows the times/multiples of CPU time between excavation scenarios SCN\#1 and SCN\#5 at six different mining levels. 


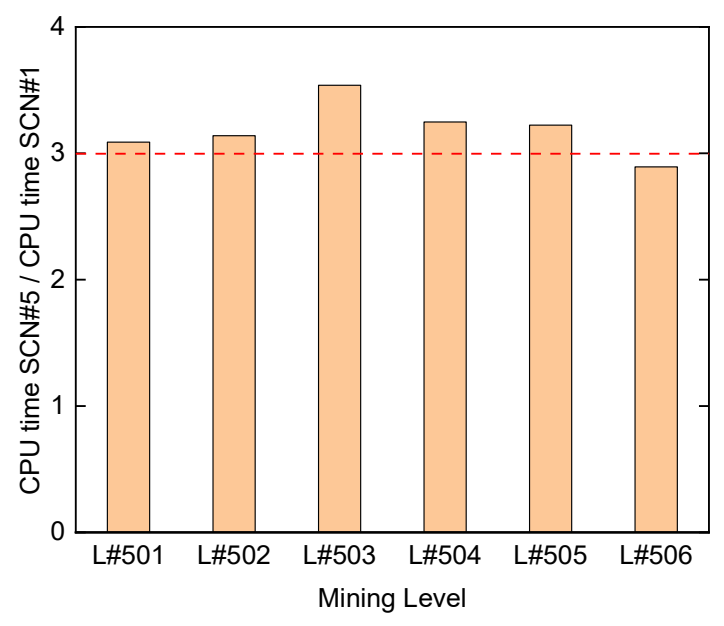

Figure 6.2. Comparison of CPU time for different excavation scenarios of different level

As shown in Figure 6.2, the CPU time used to run excavation scenario SCN\#5 is about three times the CPU time used to run excavation scenario SCN\#1. All these values at all the six different levels are approximately the same. In this case, excavation scenario SCN\#1 is more efficient and effective than SCN\#5, and it will save about $66 \%$ of the CPU time to complete the numerical simulation.

\section{Discussion}

In the actual process of stope excavation at the case study mine, some significant factors affect the stope stability, such as (i) the blast vibration caused by the blasthole stoping (BHS) mining method in the adjacent stopes, (ii) the immediately installed rock bolts and metal mesh on the stope free surfaces, and (iii) the dynamic load caused by the transportation trucks and production miners. This paper presents the study based on an assumption of the ideal mode of underground excavation scenarios; then, these influential factors are minimized.

Considering the size of the analyzed \#10 stope and the in-situ investigation, the middle of the sidewall-free surface had the maximum swellings. Then the monitoring points were chosen from there. From the above analysis of the sidewall displacement, mininginduced redistributed major principal stress, and the damage initiation (DI), excavation scenario SCN\#1 is the optimum among these proposed five different excavation scenarios in numerical modeling analysis. Considering the final status of sidewall displacement, major principal stress, and the sidewall damage initiation (DI), the excavation scenario SCN\#1 can be done in a shorter period compared with the other four excavation scenarios

As a critical factor in a numerical simulation study, the consumed CPU time to run the numerical simulation process should be considered. Therefore, an excavation scenario that considers simulation result accuracy and reasonable CPU time make the numerical modeling more productive. As shown in Figure 6.1 and Figure 6.2, compared with the other four excavation scenarios, excavation scenario SCN\#1 takes the minimum consumed CPU time to run the numerical simulation modeling analysis, and meanwhile, excavation scenario SCN\#1 achieves almost the same results in terms of the displacement, major principal stress and damage initiation on the sidewall as the other four scenarios. Therefore, compared with the other four excavation scenarios, SCN\#1 better balances the simulation results in accuracy and consumes CPU time, making it the optimum scenario among the proposed five scenarios.

\section{Conclusions}


Based on the above results and discussion about the displacement, excavation-induced redistributed major principal stress, rock mass damage initiation (DI), and the CPU time used for the numerical simulation among the five different excavation scenarios with various excavation lengths at each level, the following conclusions can be achieved.

As for displacement of both the sidewalls around the excavated stopes, compared with the other four excavation scenarios, excavation scenario SCN\#1 results in almost the same finial displacement as the other four excavation scenarios in each mining level, with the increase of the mining depth, the same excavation scenario will cause more significant finial displacement at both the sidewalls around the excavated stopes.

Excavation causes the initial stress field to redistribute, and the redistributed major principal stress may cause the rock mass damage around the excavated stopes. Here, the excavation plays a crucial role in the release of major principal stress at both sidewalls. Also, the redistributed major principal stress grows with the mining levels going deeper, corresponding to the displacement of the sidewalls. Excavation scenario SCN\#1 results in almost the same final major principal stress as the other four excavation scenarios from step S1 to step S6.

As a key indicator to assess the potential rock mass damages, the damage initiation (DI) is used here to assess the potential damages caused by the five different excavation scenarios. Due to this mine site is a hard rock mine and the size of the single stope is small compared with the large size model. Therefore, the excavation of the stope causes only minor damages to the rock mass. The excavation scenario SCN\#1 results in almost the same results as the other four excavation scenarios.

Compared with the other four excavation scenarios, excavation scenario SCN\#1 is more time-efficient as well as reliable according to the fact that it can save about $66 \%$ of the consumed CPU time and achieve almost the same final results in terms of displacement, major principal stress, and potential rock mass damage initiation (DI).

The excavation scenario of SCN\#1, which excavates the whole stope at one time, is an effective and efficient simulation excavation scenario, especially for the research focusing on the excavation-induced ground displacement and rock mass damages with a full size three-dimensional (3D) numerical model.

Supplementary Materials: The following are available online at www.mdpi.com/xxx/s1, Figure S1: title, Table S1: title, Video S1: title.

Author Contributions: Conceptualization, H.X. and D.A.; methodology, H.X. and Y.P.; software, H.X. and Y.P.; validation, H.X.; formal analysis, H.X.; investigation, H.X.; resources, H.X.; data curation, H.X.; writing-original draft preparation, H.X.; writing-review and editing, D.A.; visualization, H.X.; supervision, D.A.; project administration, D.A.; funding acquisition, D.A. All authors have read and agreed to the published version of the manuscript.

Funding: Natural Sciences and Engineering Research Council of Canada (NSERC) under the Collaborative Research and Development (CRD) Grant (NSERC RGPIN-2019-04572).

Data Availability Statement: Not Applicable.

Acknowledgments: This study was supported by the Natural Sciences and Engineering Research Council of Canada (NSERC) under the Collaborative Research and Development (CRD) Grant (NSERC RGPIN-2019-04572). The supports from China Scholarship Council were acknowledged. The supports from WestGrid and Compute/Calcul Canada were gratefully acknowledged.

Conflicts of Interest: The authors declare no conflict of interest.

\section{References}

1. Kaiser, P.K.; Diederichs, M. S.; Martin, C. D.; Sharp, J.; Steiner, W. “Underground works in hard rock tunnelling and mining,” in ISRM International Symposium, 2000, pp. 841-926.

2. Barla, G.; Bonini, M. "Time dependent deformations in squeezing tunnels," in International Association for Computer Methods and Advances in Geomechanics (IACMAG), 2008, no. October, pp. 4265-4275. 
3. Barla, G.; Debernardi, D.; Sterpi, D. "Time-dependent modeling of tunnels in squeezing conditions," Int. J. Geomech., vol. 12, no. December, pp. 697-710, 2012, doi: 10.1061/(ASCE)GM.1943-5622.0000163.

4. Barla, G. "Tunnelling under squeezing rock conditions," in Tunnelling Mechanics - Advances in Geotechnical Engineering and Tunnelling, no. December, D. Kolymbas, Ed. Berlin: P.O.Box 1675, 2001, pp. 169-268.

5. Ghaboussi, J.; Gioda, G. "On the time-dependent effects in advancing tunnels," Int. J. Numer. Anal. Methods Geomech., vol. 1, no. December 1976, pp. 249-269, 1977.

6. Golshani, A.; Oda, M.; Okui, Y.; Takemura, T.; and Munkhtogoo, E. "Numerical simulation of the excavation damaged zone around an opening in brittle rock," Int. J. Rock Mech. Min. Sci., vol. 44, pp. 835-845, 2007, doi: 10.1016/j.ijrmms.2006.12.005.

7. Tang, S.; Yu, C.; Tang, C. "Numerical modeling of the time-dependent development of the damage zone around a tunnel under high humidity conditions," Tunn. Undergr. Sp. Technol., vol. 76, no. March, pp. 48-63, 2018, doi: 10.1016/j.tust.2018.03.012.

8. Malan, D.F.; "Simulating the time-dependent behaviour of excavations in hard rock," Rock Mech. Rock Eng., vol. 35, pp. 225254, 2002, doi: 10.1007/s00603-002-0026-0.

9. Manh, H.T.; Sulem, J.; Subrin, D.; Billaux, D. "Anisotropic time-dependent modeling of tunnel excavation in squeezing ground," Rock Mech. Rock Eng., vol. 48, pp. 2301-2317, 2015, doi: 10.1007/s00603-015-0717-y.

10. Sulem, J.; Panet, M.; Guenot, A. "An Analytical Solution for Time-dependent Displacements in a Circular Tunnel," Int. J. Rock Mech. Min. Sci. Geomech. Abstr., vol. 24, no. 3, pp. 155-164, 1987.

11. Wang, T.T.; Huang, T.H. "Numerical simulation on anisotropic squeezing phenomenon of new Guanyin tunnel," J. Geoengin., vol. 6, no. 3, pp. 125-133, 2011.

12. Weng, M.; Tsai, L.; Liao, C.; Jeng, F. "Numerical modeling of tunnel excavation in weak sandstone using a time-dependent anisotropic degradation model," Tunn. Undergr. Sp. Technol., vol. 25, no. 4, pp. 397-406, 2010, doi: 10.1016/j.tust.2010.02.004.

13. Martino, J.B.; Chandler, N.A. "Excavation-induced damage studies at the Underground Research," Int. J. Rock Mech. Min. Sci., vol. 41, pp. 1413-1426, 2004, doi: 10.1016/j.ijrmms.2004.09.010.

14. Kishida; K.; Kikumoto, M.; Cui, Y.; Kimura, M. "Advanced numerical simulation of tunnel excavation and its application to the shallow overburden tunnel on unconsolidated ground," in Innovative Numerical Modelling in Geomechanics, Taylor \& Francis Group, 2012, pp. 77-93.

15. Funatsu, T.; Hoshino, T.; Swae, H.; Shimizu, N. "Numerical analysis to better understand the mechanism of the effects of ground supports and reinforcements on the stability of tunnels using the distinct element method," Tunn. Undergr. Sp. Technol., no. 2003, pp. 561-573, 2008, doi: 10.1016/j.tust.2007.10.003.

16. Zhang, Q.; Wang, J.; Wang, W.; Bai, S.; Lin, P. "Study on slope stability due to the influence of excavation of the high-speed rail tunnel," Geomatics, Nat. Hazards Risk, vol. 10, no. 1, pp. 1193-1208, 2019, doi: 10.1080/19475705.2019.1568311.

17. Kielbassa, S.; and Duddeck, H. "Stress-strain fields at the tunnelling face-three-dimensional analysis for two-dimensional technical approach," Rock Mech. Rock Eng., no. 1988, pp. 115-132, 1991.

18. Gioda, G.; Cividini, A. "Numerical methods for the analysis of tunnel performance in squeezing rocks," Rock Mech. Rock Eng., vol. 29, pp. 171-193, 1996.

19. Eberhardt, E. "Numerical modelling of three-dimension stress rotation ahead of an advancing tunnel face," Int. J. Rock Mech. Min. Sci., vol. 38, pp. 499-518, 2001.

20. Sepehri, M.; Apel, D.B.; Hall, R.A. "Prediction of mining-induced surface subsidence and ground movements at a Canadian diamond mine using an elastoplastic finite element model," Int. J. Rock Mech. Min. Sci., vol. 100, no. October, pp. 73-82, 2017, doi: 10.1016/j.ijrmms.2017.10.006.

21. Sepehri, M.; Apel, D.B.; Adeeb, S.; Leveille, P.; Hall, R.A. "Evaluation of mining-induced energy and rockburst prediction at a diamond mine in Canada using a full 3D elastoplastic fi nite element model," Eng. Geol., vol. 266, no. December 2019, p. 105457, 2020, doi: 10.1016/j.enggeo.2019.105457.

22. Pellet, F.; Roosefid, M.; Deleruyelle, F. "On the 3D numerical modelling of the time-dependent development of the damage zone around underground galleries during and after excavation," Tunn. Undergr. Sp. Technol., vol. 24, no. 6, pp. 665-674, 2009, doi: 10.1016/j.tust.2009.07.002.

23. Kasper, T.; Meschke, G. "A 3D finite element simulation model for TBM tunnelling in soft ground," Int. J. Numer. Anal. Methods Geomech., vol. 1460, no. July, pp. 1441-1460, 2004, doi: 10.1002/nag.395.

24. Langford, M.P.C; Ghazvinian, E.; Diederichs, M. "Numerical delineation of the excavation damage zones : From rock properties to statistical distribution of the dimensions," in Eurock 2012- the 2012 ISRM International Symposium, 2012, no. 28-30 May, Stockholm, Sweden.

25. Dassault Systèmes Simulia Corp., "Analysis User's Manual Volume 1: Introduction, Spatial modeling, execution and output," Abaqus 6.12, vol. I, 2012.

26. Leveille P., Sepehri M., Apel D. B., "Rockbursting potential of Kimberlite : a case study of Diavik Diamond Mine," Rock Mech. Rock Eng., vol. 50, no. 12, pp. 3223-3231, 2017, doi: 10.1007/s00603-017-1294-z.

27. Lingga, B.A. "Investigation of Cemented Rockfill Properties Used at a Canadian Diamond Mine," Master's thesis, University of Alberta, Edmonton, Canada, 2018.

28. Castro, L.A.; Bewick, R.P.; Carter, T.G. "An overview of numerical modelling applied to deep mining," in Innovative Numerical Modelling in Geomechanics, no. May, M. M. F. Eurípedes Vargas Jr., Roberto Azevedo, L. Ribeiro e Sousa, Ed. London: CRC Press, 2012, pp. 393-414. 
29. Castro, L.A.; Grabinsky, M.W.; McCreath, D.R. "Damage initiation through extension fracturing in a moderately jointed brittle rock mass," Int. J. Rock Mech. Min. Sci., vol. 34, no. 110, pp. 110e.1-110e.13, 1997. 